\title{
The effect of endometrial thickness on pregnancy outcome in patients with Asherman's syndrome post-hysteroscopic adhesiolysis
}

This article was published in the following Dove Press journal: International Journal of Women's Health

\author{
Saeed Baradwan' \\ Dina Shafi' \\ Amira Baradwan² \\ Muhammad Salman Bashir ${ }^{3}$ \\ Dania Al-Jaroudi, ${ }^{1,4}$ \\ 'Department of Obstetrics and \\ Gynecology, Women's Specialized \\ Hospital, King Fahad Medical \\ City, Riyadh, ${ }^{2}$ Faculty of Medicine, \\ King Abdulaziz University, Jeddah, \\ ${ }^{3}$ Research Center, King Fahad \\ Medical City, Riyadh, ${ }^{4}$ Department \\ of Obstetrics and Gynecology, \\ Reproductive Infertility and Medicine \\ Department, King Fahad Medical City, \\ Riyadh, Saudi Arabia
}

Background: Hysteroscopic adhesiolysis anatomically restores the uterine cavity in cases of Asherman's syndrome (AS); however, the extent of endometrial fibrosis could determine the pregnancy outcome.

Objectives: To determine whether endometrial thickness could influence pregnancy outcome of hysteroscopic adhesiolysis in women with a history of AS.

Subjects and methods: This was a retrospective cohort study that included 41 women who attended Women's Specialized Hospital, King Fahad Medical City from December 2008 to December 2015, presented with a history of infertility or recurrent pregnancy loss, and were diagnosed with intrauterine adhesions and treated by hysteroscopic adhesiolysis. To analyze the causative factors of AS, history of curettage, miscarriage, postpartum hemorrhage, hysteroscopy, endometritis, and any uterine surgery were recorded. Patients were followed up for 2 years to account for pregnancy. Patients were divided into two groups based on measurement of endometrial thickness in the midsagittal plane at mid-cycle of a menstrual period. Group A consisted of 26 patients with endometrial thickness $\leq 5 \mathrm{~mm}$, and group B included 15 patients with endometrial thickness $>5 \mathrm{~mm}$. The main outcome measures included endometrial thickness and pregnancy outcome.

Results: Group A had significantly $(P<0.001)$ lower pregnancy rates compared with group B (38.4\% versus $80 \%$, respectively). Five of 10 pregnancies $(50 \%)$ from group A miscarried, compared with 1 of $12(8.3 \%)$ pregnancies in group B. This was statistically significant $(P<0.001)$.

Conclusion: Pregnancy rates were observed to be higher when the endometrium was $>5 \mathrm{~mm}$ in thickness among patients with AS and miscarriage rates may be reduced in this group.

Keywords: intrauterine adhesion, operative hysteroscopy, Asherman's syndrome, endometrial thickness

\section{Introduction}

The endometrium undergoes cyclic changes during the menstrual cycle to prepare for implantation. ${ }^{1}$ A thin endometrium that fails to respond to hormones leads to implantation failure or early miscarriages due to lack of blood supply. ${ }^{2}$ Asherman's syndrome (AS) causes endometrial fibrosis. This leads to a stroma that is largely replaced with fibrous tissue and glands that are replaced by inactive cubocolumnar endometrial epithelium. ${ }^{3}$ The distinction between the functional and basal layers of the endometrium is lost. The functional layer is replaced by an epithelial monolayer unresponsive to hormonal stimulation, and the fibrotic adhesion forms across the cavity. In other cases, there may be calcification or even ossification in the stroma.
Correspondence: Saeed Baradwan Department of Obstetrics and Gynecology, Women's Specialized Hospital, King Fahad Medical City, PO Box 59046, Riyadh II525,

Saudi Arabia

Tel +966 || 2889999 ext 13210

Fax +966 | 2889999 ext $37 \mid 4$

Email dr.saeed_bardwan@yahoo.com
International Journal of Women's Health 2018:10 77-82

77

Dovepress f in 0

http://dx.doi.org/10.21474IWHSI51203 (c) (1) (5) 2018 Baradwan et al. This work is published and licensed by Dove Medical Press Limited. The full terms of this license are available at https://www.dovepress.com/terms.php (c) $\mathrm{BY}$ and incorporate the Creative Commons Attribution - Non Commercial (unported, v3.0) License (http://creativecommons.org/licenses/by-nc/3.0/). By accessing the work you hereby accept the Terms. Non-commercial uses of the work are permitted without any further permission from Dove Medical Press Limited, provided the work is properly attributed. For permission for commercial use of this work, please see paragraphs 4.2 and 5 of our Terms (https://www.dovepress.com/terms.php). 
The tissue is usually avascular. The intrauterine adhesions may involve different layers of the endometrium, myometrium, or connective tissue, ${ }^{4,5}$ thus leading to implantation failure and miscarriages. ${ }^{6}$ Hysteroscopy is now the gold standard of diagnosis and treatment since it provides a good view of the cavity, allowing a fairly precise description of the location and degree of adhesions and concurrent treatment of adhesions. ${ }^{7,8}$ However, the extent of endometrial fibrosis will determine the reproductive outcome after an anatomic restoration of the uterus. Surgical success is mainly achieved by the release of adhesions, and therefore, redevelopment of adhesions remains a limiting step to the success of the surgery. ${ }^{9}$ Generally, both endometrial thickness and endometrial pattern have been regarded as indicators for endometrial receptivity. Additionally, assessment of the association between these sonographic endometrial characteristics and clinical outcomes following in vitro fertilization (IVF) treatments has been the focus of interest for many years. However, no consensus was achieved on whether the endometrial ultrasound (USG) characteristics can predict the pregnancy outcome in patients with AS.

This study aimed to analyze the outcome of hysteroscopic adhesiolysis in 41 women with AS by observing the effect of endometrial thickness on pregnancy outcome.

\section{Subjects and methods}

An analytical retrospective cohort study was carried out, which included 41 women who attended Women's Specialized Hospital, King Fahad Medical City in Riyadh, Saudi Arabia, between January 2008 and December 2015 and presented with a history of infertility, recurrent pregnancy loss, or menstrual period disturbance and were diagnosed with intrauterine adhesions by hysteroscopy. King Fahad Medical City Institutional review board (IRB) approval was granted for the study (number 15-440).

All of the patients underwent preoperative evaluations, including a detailed history, age, height, weight, body mass index, types and duration of infertility, pattern of the past menstrual cycle, baseline transvaginal USG, tubal patency test, and spouse's semen analysis. Serum hormone measurements (estradiol [E2], progesterone [P] androgens, luteinizing hormone, follicle-stimulating hormone [FSH], and prolactin) were evaluated on the fifth day of the menstrual cycle or at a randomly chosen time in patients who had amenorrhea. Patients diagnosed with intrauterine adhesions and no other demonstrable causes of infertility were considered in the study.

To analyze the causative factors of AS, history of curettage, miscarriage, postpartum hemorrhage, hysteroscopy, endometritis, and any uterine surgery such as myomectomy and cesarean section was recorded. Patients with male factor infertility, age above 40 years, ovarian failure (FSH $>40$ $\mathrm{U} / \mathrm{L})$, an abnormal hormonal profile that might affect the reproductive success, or any other uterine malformation such as fibroid uterus or bilateral blocked tubes were excluded from the study.

Hysteroscopic adhesiolysis was performed for all patients by four experienced surgeons in our unit using similar techniques under general anesthesia. The cervix was initially dilated to " 12 " using Hegar's dilators. An $8 \mathrm{~mm}, 12^{\circ}$ rigid telescope using bipolar electrode needle or loop under direct vision was used. Normal saline was used as a distending medium through an automated hysteroscopic distension pump. Adhesiolysis began inferiorly and proceeded toward fundus until a panoramic view of the cavity was obtained and both ostia were visualized. In cases of adhesions in the cervical canal, Hegar's dilators were used to sound and dilate the cervical canal under USG guidance. The procedure was discontinued even if both ostia were not visualized when the pink myometrium was seen.

Concurrent laparoscopy was done in patients in whom tubal factor infertility was also suspected or hysteroscopy required laparoscopic guidance. In some cases, transabdominal B-mode USG was also used to guide the surgeon during the procedure. Cefazolin sodium ( $2 \mathrm{~g}$ ) was administered to all patients during the operation.

All cases were diagnosed hysteroscopically and classified according to the March classification of AS (mild if filmy adhesion occupied less than one-quarter of the uterine cavity and the ostial areas and upper fundus were minimally involved; clear, moderate if one-fourth to three-fourths of the cavity was involved and the ostial areas and upper fundus were partially involved and there was no agglutination of uterine walls; or severe if more than three-fourths of the cavity was involved and there were occlusion of both ostial area and upper fundus and agglutination of uterine walls). ${ }^{10}$

Postoperatively, all patients were given cyclical hormonal therapy for 3 months, Premarin $0.625 \mathrm{mg}$ for 14 days, and Primolut $5 \mathrm{mg}$ three times a day added on the last 7 days.

Transvaginal USG was done to measure the endometrial thickness in the midsagittal plane at the mid-cycle of the menstrual period, and if assisted reproductive technology was planned for, then the measurement was done on the day of embryo transfer. Measurements were made from the outer edge of the endometrial-myometrial interface to the outer edge in the widest part of the endometrium. Patients were divided into two groups based on measurement of endometrial thickness in the midsagittal plane at the mid-cycle of the menstrual period. Group A consisted of 26 patients with 
an endometrial thickness $\leq 5 \mathrm{~mm}$, and group B included 15 patients with an endometrial thickness $>5 \mathrm{~mm}$.

Patients were followed up every 3 months for a period of 6 months to 2 years. Details of spontaneous conception and reproductive outcome were recorded. Ovulation induction, intrauterine insemination, IVF, or intracytoplasmic sperm injection was done in patients who had tubal factor infertility or were unable to conceive spontaneously during 1 year.

Patients undergoing assisted reproduction technology were booked for antagonist protocol. Cetrorelix (MerckSerono, Darmstadt, Germany) $0.25 \mathrm{mg}$ was started on day 6 of ovarian stimulation by either r-FSH or human menopausal gonadotropins until the day of human chorionic gonadotropin (HCG) trigger. Monitoring was started on day 7 of ovarian stimulation by measuring estradiol level; follicle growth and endometrial response were followed using transvaginal USG. HCG $(10,000 \mathrm{IU})$ was given intramuscularly when at least two follicles had reached $18 \mathrm{~mm}$ or three follicles were within $16 \mathrm{~mm}$ in diameter. Transvaginal oocyte retrieval was carried out 36 hours after the HCG injection under paravaginal block by $1 \%$ Lidocaine. The oocytes were fertilized on the day of retrieval, and cleavage-stage embryos were transferred on day 2, 3, or 5 after oocyte retrieval. One or two embryos were transferred to all patients unless they were above the age of 40 and had multiple IVF failures.

The main outcome measure was to identify the endometrial thickness and positive pregnancy test which might have ended in miscarriage, ectopic pregnancy, preterm, term, or no pregnancy and ongoing viable pregnancy which was confirmed by early USG scan.

All data were entered and analyzed through statistical package SPSS version 22. Chi-square test was applied to determine the significant relationship between pregnancy outcome and other study parameters. A $P$-value $<0.05$ was considered statistically significant.

\section{Ethical approval}

King Fahad Medical City IRB approval was granted for the study (number 15-440). Due to the study being retrospective, as per our institution policy, only IRB approval is needed before conducting the study. Patient consent was waived as no patient identifiers were obtained, and the patient care was not affected or influenced in any way. This article does not contain any study performed with animals by any of the authors.

\section{Results}

The study included 41 women. Their mean age $( \pm \mathrm{SD})$ was $32.24( \pm 4.61)$ years, whereas their mean body mass index $\left( \pm\right.$ SD) was $29.07( \pm 3.60) \mathrm{kg} / \mathrm{m}^{2}$. Mean duration of infertility $( \pm \mathrm{SD})$ was 6.12 years $( \pm 3.87)$. Their clinical characteristics are presented in Table 1. Hypomenorrhea was reported by $46.3 \%$ of the pregnant women, whereas amenorrhea was reported by $14.6 \%$ of the pregnant women. Also, $63.4 \%$ had dysmenorrhea. Secondary infertility was reported by most of them $(70.7 \%)$, whereas primary infertility was seen among the remaining women (29.3\%). Miscarriage, curettage, and postpartum hemorrhage were reported by $56.1 \%, 51.2 \%$, and $31.7 \%$ of them, respectively. Open myomectomy, hysteroscopy, and endometritis were reported by $12.2 \%, 31.7 \%$, and $34.1 \%$, of the participants, respectively. About $36.6 \%$ had a previous cesarean section. Hysteroscopy alone was reported by $53.7 \%$ of cases, whereas hysteroscopy with laparoscopy

Table I Clinical characteristics of patients $(\mathrm{N}=4 \mathrm{I})$

\begin{tabular}{|c|c|}
\hline Characteristics & n (\%) \\
\hline \multicolumn{2}{|l|}{ Menstrual pattern } \\
\hline Normal & $16(39)$ \\
\hline Hypomenorrhea & $19(46.3)$ \\
\hline Amenorrhea & $6(14.6)$ \\
\hline Dysmenorrhea & $26(63.4)$ \\
\hline Primary infertility & $12(29.3)$ \\
\hline Secondary infertility & $29(70.7)$ \\
\hline History of miscarriages & $23(56.1)$ \\
\hline History of curettage & $21(51.2)$ \\
\hline History of PPH & $13(3 \mid .7)$ \\
\hline History of open myomectomy & $5(12.2)$ \\
\hline History of hysteroscopy & $13(3 \mid .7)$ \\
\hline History of endometritis & $14(34.1)$ \\
\hline History of cesarean section & $15(36.6)$ \\
\hline \multicolumn{2}{|l|}{ Operative type } \\
\hline Hysteroscopy alone & $22(53.7)$ \\
\hline Hysteroscopy + US & $4(9.8)$ \\
\hline Hysteroscopy + laparoscopy & $15(36.6)$ \\
\hline \multicolumn{2}{|l|}{ Endometrial thickness } \\
\hline$\leq 5$ & $26(63.4)$ \\
\hline$>5$ & $15(36.6)$ \\
\hline \multicolumn{2}{|l|}{ March classification } \\
\hline Minimal & $14(34.1)$ \\
\hline Moderate & $17(4 \mid .5)$ \\
\hline Severe & $10(24.4)$ \\
\hline \multicolumn{2}{|l|}{ Conception methods } \\
\hline Spontaneous & $15(36.6)$ \\
\hline IVF & $16(39)$ \\
\hline IUI & $4(9.8)$ \\
\hline ICSI & $2(4.9)$ \\
\hline Induced & $4(9.8)$ \\
\hline \multicolumn{2}{|l|}{ Pregnancy outcome } \\
\hline Ectopic & $2(4.9)$ \\
\hline Miscarriage & $6(14.6)$ \\
\hline Preterm & $5(12.2)$ \\
\hline Term & $9(22)$ \\
\hline No Pregnancy & $19(46.3)$ \\
\hline
\end{tabular}

Abbreviations: ICSI, intracytoplasmic sperm injection; IUI, intrauterine insemination; IVF, in vitro fertilization; PPH, postpartum hemorrhage; US, ultrasound. 
was reported by $36.6 \%$ of cases. Endometrial thickness was $>5 \mathrm{~mm}$ in $12(36.6 \%)$ patients and $\leq 5 \mathrm{~mm}$ in $26(63.4 \%)$ patients. Also, $41.5 \%$ and $24.4 \%$ of cases were moderate and severe, respectively, according to March classification. The most frequent conception methods used were IVF (39\%) and spontaneous (36.6\%). Preterm and ectopic pregnancies were reported by $12.2 \%$ and $4.9 \%$ of cases, respectively.

From Table 2, it is evident that among the studied factors that could be associated with endometrial thickness, menstrual period pattern, previous history of cesarean section, and March classification were significantly associated with endometrial thickness. Amenorrhea was reported by $23.1 \%$ of women in group $\mathrm{A}$, compared to $0 \%$ in group $\mathrm{B}(P=0.002)$.

Table 2 Association between demographic characteristics and endometrial thickness

\begin{tabular}{|c|c|c|c|}
\hline \multirow[t]{2}{*}{ Characteristics } & \multicolumn{2}{|c|}{ Endometrial thickness } & \multirow[t]{2}{*}{$P$-value } \\
\hline & $\begin{array}{l}\text { Group A }(n=26), \\
\leq 5 \mathrm{~mm}\end{array}$ & $\begin{array}{l}\text { Group B }(n=15) \text {, } \\
>5 \mathrm{~mm}\end{array}$ & \\
\hline Age (mean $\pm S D)$ & $33.15 \pm 3.5 \mid$ & $30.67 \pm 5.87$ & 0.151 \\
\hline BMI (mean \pm SD) & $6.62 \pm 4.33$ & $5.27 \pm 2.84$ & 0.237 \\
\hline \multicolumn{4}{|c|}{ Menstrual period $(\%)$} \\
\hline Normal & $5(19.2)$ & II (73.3) & $0.002 *$ \\
\hline Hypomenorrhea & $15(57.7)$ & $4(26.7)$ & \\
\hline Amenorrhea & $6(23.1)$ & $0(0.0)$ & \\
\hline \multicolumn{4}{|l|}{ Miscarriages (\%) } \\
\hline No & $10(38.5)$ & $8(53.3)$ & 0.355 \\
\hline Yes & $16(61.5)$ & $7(46.7)$ & \\
\hline \multicolumn{4}{|l|}{ Curettage (\%) } \\
\hline No & II (42.3) & $9(60.0)$ & 0.275 \\
\hline Yes & I5 (57.7) & $6(40.0)$ & \\
\hline \multicolumn{4}{|l|}{ History of PPH (\%) } \\
\hline No & $17(65.4)$ & II (73.3) & 0.598 \\
\hline Yes & $9(34.6)$ & $4(26.7 \%)$ & \\
\hline \multicolumn{4}{|c|}{ Open myomectomy (\%) } \\
\hline No & $24(92.3)$ & $12(80.0)$ & 0.246 \\
\hline Yes & $2(7.7)$ & $3(20.0)$ & \\
\hline \multicolumn{4}{|l|}{ Endometritis (\%) } \\
\hline No & $19(73.1)$ & $8(53.3)$ & 0.199 \\
\hline Yes & $7(26.9)$ & $7(46.7)$ & \\
\hline \multicolumn{4}{|c|}{ History of cesarean section (\%) } \\
\hline No & $13(50.0)$ & $13(86.7)$ & $0.019 *$ \\
\hline Yes & $13(50.0)$ & $2(13.3)$ & \\
\hline \multicolumn{4}{|c|}{ March classification (\%) } \\
\hline Minimal & $3(11.5)$ & II (73.3) & $<0.00 I^{*}$ \\
\hline Moderate & $13(50.0)$ & $4(26.7)$ & \\
\hline Severe & $10(38.5)$ & $0(0.0)$ & \\
\hline \multicolumn{4}{|c|}{ Conception methods (\%) } \\
\hline Spontaneous & II (42.3) & $4(26.7)$ & 0.325 \\
\hline IVF & $10(38.5)$ & $6(40.0)$ & \\
\hline IUI & I (3.8) & $3(20.0)$ & \\
\hline ICSI & $2(7.7)$ & $0(0.0)$ & \\
\hline Induced & $2(7.7)$ & $2(13.3)$ & \\
\hline
\end{tabular}

Note: *Statistically significant.

Abbreviations: ICSI, intracytoplasmic sperm injection; IUI, intrauterine insemination; IVF, in vitro fertilization; PPH, postpartum hemorrhage.
Group B had significantly $(P=0.019)$ lower previous history of cesarean section rate compared with group A $(13.3 \%$ versus $50 \%$, respectively). Ten of 26 pregnancies $(50 \%)$ from group A had severe form in hysteroscopic March classification, compared with 0 of $15(0 \%)$ in group B. This was statistically significant $(P<0.001)$. There was no statistical significance when the conception methods were compared to endometrial thickness $(P=0.325)$.

It is evident from Table 3 that group A had significantly $(P<0.001)$ lower pregnancy rates compared to group $\mathrm{B}$ (38.4\% versus $80 \%$, respectively). Five of 10 pregnancies $(50 \%)$ from group A miscarried, compared to 1 of $12(8.3 \%)$ pregnancies in group B. This was statistically significant $(P<0.001)$.

\section{Discussion}

This study reports the pregnancy outcomes of 41 cases of hysteroscopic adhesiolysis for AS. The clinical characteristics of the patients in this study were comparable to those of other studies. ${ }^{11-14}$ In accordance with other reports, ${ }^{15}$ history of curettage was reported by $51.2 \%$ of AS cases. Amenorrhea was reported by $23.1 \%$ and previous cesarean section by $50 \%$ of women with AS who had thin endometrium ( $<5 \mathrm{~mm})$.

Endometrial thickness is considered as a reflection of the degree of endometrial proliferation in the absence of intrauterine pathology. ${ }^{16}$ It was measured in the midsagittal plane during transvaginal USG scan. In this study, lower pregnancy rates were observed with endometrial thickness $<5 \mathrm{~mm}$ group. Overall, the association between endometrial thickness and pregnancy outcome was statistically significant. Results from the literature are conflicting. In addition to endometrial thickness, the correlation between endometrial pattern and the outcome of assisted reproductive techniques has also been the focus of interest for many years. However, their conclusions were not consistent. Dickey et al ${ }^{17}$ found that reproduction had increased when the endometrium was at least $9 \mathrm{~mm}$ thick and had a triple-line appearance during IVF cycles. However, biochemical pregnancies were more frequent with a thinner endometrium. On the other hand, Check et $\mathrm{al}^{1}$ reported an improved pregnancy rate with a thicker endometrium. Noyes et $\mathrm{al}^{18}$ observed pregnancy and ongoing pregnancy rates to be higher when the endometrial thickness was $>9 \mathrm{~mm}$. Quite similarly, Rinaldi et al ${ }^{19}$ reported that minimum thickness of $10 \mathrm{~mm}$ during IVF was associated with a higher pregnancy rate.

In more recent studies, ${ }^{8,16,20-22}$ however, no significant association between endometrial thickness and pregnancy outcome was seen. Relatively small sample size in these 
Table 3 Association between endometrial thickness and pregnancy outcome

\begin{tabular}{lllllllll}
\hline $\begin{array}{l}\text { Endometrial } \\
\text { thickness (mm) }\end{array}$ & $\mathbf{n}$ & \multicolumn{2}{l}{ Pregnancy outcome } & P-value \\
\cline { 3 - 8 } & & Pregnancy (\%) & Ectopic (\%) & Miscarriage (\%) & Preterm (\%) & Term (\%) & No pregnancy (\%) \\
\hline$\leq 5$ & 26 & $10(38.46)$ & $0(0.0)$ & $5(19.23)$ & $2(7.7)$ & $3(11.5)$ & $16(61.53)$ & $0.013^{*}$ \\
$>5$ & 15 & $12(80)$ & $2(13.3)$ & $1(6.66)$ & $3(20)$ & $6(40)$ & $3(20)$ & \\
\hline
\end{tabular}

Note: *Statistically significant.

studies could have limited power to detect a small difference from the statistical point of view.

It is possible that, with more advanced laboratory and stimulation methods, a small effect of endometrial thickness on outcome might become obscured or overridden. The day of measurement might also influence the association between endometrial thickness and cycle outcome. ${ }^{16}$

Additionally, the influence of "increased" endometrial thickness has been evaluated in other studies. Weissman et $\mathrm{al}^{23}$ observed lower implantation and pregnancy rates among women with an endometrial thickness $>14 \mathrm{~mm}$ on the day of HCG administration. However, Dietterich et $\mathrm{al}^{24}$ reported no adverse impact of thickened endometrium $(>14 \mathrm{~mm})$ on implantation, pregnancy, or abortion rates.

Kovacs et $\mathrm{al}^{16}$ observed that pregnancy rates were higher when an endometrial thickness of at least $10 \mathrm{~mm}$ was reached. Although the improvement was small in their study, they suggested that adequate endometrial development is one of the factors that play a significant role in IVF outcome. This study suggests the same.

Among the limitations of this study is the fact that the study sample was relatively small as it was limited to Women's Specialized Hospital, which could affect the generalizability of results. An important limitation of our study is that it is retrospective in nature. We relied on records in this study, of which some were incomplete, particularly regarding miscarriage information (types, gestational age, and the chromosomal analysis of chorionic villi). Despite these limitations, we found a relationship between pregnancy outcome and endometrial thickness among women with AS. In the light of the study results, we recommend conducting a study with adequate sample size to increase the study power and thus provide more generalizable results.

\section{Conclusion}

The results of this study suggest that adequate endometrial thickness is required for pregnancy to occur, and the pregnancy rates were observed to be higher when the endometrium was at least $5 \mathrm{~mm}$ in thickness among patients with AS. This information might aid physicians in guiding their patients and taking optimal clinical decisions together.

\section{Disclosure}

The authors report no conflicts of interest in this work.

\section{References}

1. Check JH, Nowroozi K, Choe J, Dietterich C. Influence of endometrial thickness and echo patterns on pregnancy rates during in vitro fertilization. Fertil Steril. 1991;56(6):1173-1175.

2. Senturk LM, Erel CT. Thin endometrium in assisted reproductive technology. Curr Opin Obstet Gynecol. 2008;20(3):221-228.

3. Foix A, Bruno RO, Davison T, Lema B. The pathology of postcurettage adhesions. Am J Obstet Gynecol. 1966;96(7):1027-1033.

4. McCulloch TA, Wagner B, Duffy S, Barik S, Smith JH. The pathology hysterectomy specimens following trans-cervical resection of the endometrium. Histopathology. 1995;27(6):541-547.

5. Katz Z, Ben-Arie A, Lurie S, Manor M, Insler V. Reproductive outcome following hysteroscopic adhesiolysis in Asherman's syndrome. Int $J$ Fertil Menopausal Stud. 1996;41(5):462-465.

6. Buckley $\mathrm{CH}$. Normal endometrium and non-proliferative conditions of the endometrium. In: Fox H, Wells M, editors. Obstetrical and Gynaecological Pathology. 5th ed. London: Churchill Livingstone; 2002:391-442.

7. Wamsteker K, Blok SD. Diagnostic hysteroscopy: technique and documentation. In: Sutton C, Diamond M, editors. Endoscopic Surgery for Gynecologists. Philadelphia, PA: WB Saunders; 1993.

8. Bassil S. Changes in endometrial thickness, width, length and pattern in predicting pregnancy outcome during ovarian stimulation in in vitro fertilization. Ultrasound Obstet Gynecol. 2001;18(3):258-263.

9. Preutthipan S, Linasmita V. Reproductive outcome following hysteroscopic lysis of intrauterine adhesions: a result of 65 cases at Ramathibodi Hospital. J Med Assoc Thai. 2000;83(1):42-46.

10. March C, Israel R. Intrauterine adhesions secondary to elective abortion. Hysteroscopic diagnosis and management. Obstet Gynecol. 1976;48(4): 422-429.

11. Bhandari S, Bhave P, Ganguly I, Baxi A, Agarwal P. Reproductive outcome of patients with Asherman's syndrome: a SAIMS experience. J Reprod Infertil. 2015;16(4):229-235.

12. Yu D, Wong YM, Cheong Y, Xia E, Li TC. Asherman syndrome one century later. Fertil Steril. 2008;89(4):759-779.

13. Yu D, Li TC, Xia E, Huang X, Liu Y, Peng X. Factors affecting reproductive outcome of hysteroscopic adhesiolysis for Asherman's syndrome. Fertil Steril. 2008;89(3):715-722.

14. Roy KK, Baruah J, Sharma JB, Kumar S, Kachawa G, Singh N. Reproductive outcome following hysteroscopic adhesiolysis in patients with infertility due to Asherman's syndrome. Arch Gynecol Obstet. 2010; 281(2):355-361.

15. Conforti A, Alviggi C, Mollo A, De Placido G, Magos A. The management of Asherman syndrome: a review of literature. Reprod Biol Endocrinol. 2013;11:118.

16. Kovacs P, Matyas S, Boda K, Kaali SG. The effect of endometrial thickness on IVF/ICSI outcome. Hum Reprod. 2003;18(11):2337-2341.

17. Dickey RP, Olar TT, Curole DN, Taylor SN, Rye PH. Endometrial pattern and thickness associated with pregnancy outcome after assisted reproduction technologies. Hum Reprod. 1992;7(3):418-421.

18. Noyes N, Liu HC, Sultan K, Schattman G, Rosenwaks Z. Endometrial thickness appears to be a significant factor in embryo implantation in in-vitro fertilization. Hum Reprod. 1995;10(4):919-922. 
19. Rinaldi L, Lisi F, Floccari A, Lisi R, Pepe G, Fishel S. Endometrial thickness as a predictor of pregnancy after in-vitro fertilization but not after intracytoplasmic sperm injection. Hum Reprod. 1996;11(7): 1538-1541.

20. Yuval Y, Lipitz S, Dor J, Achiron R. The relationships between endometrial thickness, and blood flow and pregnancy rates in in-vitro fertilization. Hum Reprod. 1999;14(4):1067-1071.

21. De Geyter C, Schmitter M, De Geyter M, Nieschlag E, Holzgreve W, Schneider HP. Prospective evaluation of the ultrasound appearance of the endometrium in a cohort of 1,186 infertile women. Fertil Steril. 2000; 73(1):106-113.

22. Schield RL, Knobloch C, Dorn C, Fimmers R, van der Ven H, Hansmann M. Endometrial receptivity in an in vitro fertilization program as assessed by spiral artery blood flow, endometrial thickness, endometrial volume, and uterine artery blood flow. Fertil Steril. 2001;75(2): $361-366$.
23. Weissman A, Gotlieb L, Casper RF. The detrimental effect of increased endometrial thickness on implantation and pregnancy rates and outcome in an in vitro fertilization program. Fertil Steril. 1999;71(1): 147-149.

24. Dietterich C, Check JH, Choe JK, Nazari A, Lurie D. Increased endometrial thickness on the day of human chorionic gonadotropin injection does not adversely affect pregnancy or implantation rates following in vitro fertilization-embryo transfer. Fertil Steril. 2002;77(4): 781-786.

\section{Publish your work in this journal}

The International Journal of Women's Health is an international, peerreviewed open-access journal publishing original research, reports, editorials, reviews and commentaries on all aspects of women's healthcare including gynecology, obstetrics, and breast cancer. The manuscript management system is completely online and includes a very quick and fair peer-review system, which is all easy to use. Visit http://www.dovepress.com/testimonials.php to read real quotes from published authors.

Submit your manuscript here: http://www.dovepress.com/international-journal-of-womens-health-journal 